\title{
UM TRIBUTO AO JOGO TEATRAL
}

\section{A tribute to the theater game}

\author{
Newton Armani de Souza \\ Universidade Federal de Goiás - UFG
}

Resumo: O texto emprega a noção de "tributo", enquanto conceito extraído da cultura do Samba de Carnaval, para que eu possa cartografar minha trajetória pessoal, como artista e educador, formado no curso de Especialização em Teatro e Dança, da Universidade de São Paulo, em 1991. Partindo do ponto de vista sobre o desenvolvimento pessoal, procuro ressaltar como, no programa da Especialização, a prática do Jogo Teatral vinha coerentemente acompanhada pelo exercício dos princípios da Eutonia, e do Método Laban. Em seguida, procuro demonstrar o grau de influência que o Sistema de Spolin exerceu sobre algumas das experiências mais relevantes da minha trajetória profissional.

Palavras-chave: Jogo Teatral; Eutonia; Método Laban; Polifonia.

Abstract: The text uses the notion of "tribute", as a concept extracted from the culture of Carnival's Samba, so that I can map my personal trajectory, as an artist and educator, graduated in the Specialization course in Theater and Dance, at the University of São Paulo, Starting from the point of view of personal development, I try to emphasize how, in the Specialization program, the practice of the Theater Game came, consistently accompanied by the exercise of the principles of Eutonia, and the Laban Method. Then, I try to demonstrate the influence degree that the Spolin System has had over some of the most relevant experiences in my professional career.

Keywords: Theater game; Eutony; Laban method; Polyphony. 
Oferecer uma contribuição para essa publicação significa elaborar um tributo. Doutorei-me recentemente, na Faculdade de Letras, da Universidade de Lisboa, estudando a teatralidade das escolas de samba de São Paulo, minha terra natal. Um tributo, na cultura do samba, é uma homenagem, uma exaltação.

$\mathrm{Na}$ análise do primeiro espetáculo que dirigi, em 1991, uma montagem de teatro de rua, em Itaquera, um dos bairros mais populosos de toda a região metropolitana da capital, na Casa de Cultura "Raul Seixas", com 80 atores, em sua maioria com pouca ou nenhuma experiência em teatro, encenamos um "samba de exaltação". Exaltamos a figura de um personagem anônimo da história coletiva da comunidade do bairro de Itaquera (SOUZA, 2019). Sem o jogo teatral, eu não teria contribuído para levar ao público 13 apresentações de "O nome do negro", em dezenas de Casas de Cultura e em frente ao Teatro Municipal de São Paulo e ainda no vão do MASP. O samba me ensinou o que era exaltar um indivíduo, ou um valor, em dimensão espetacular, alegoricamente representado por um enorme contingente de vozes, divididas em diversos grupos corais. Polifonia, como diria Bakhtin (1987). Exaltar Spolin significa demonstrar como o jogo teatral esteve presente nessa e em todas as experiências relevantes da minha vida profissional, como artista e docente.

Fui educado com base na famigerada Lei 5.692/71 e posso afirmar que o ensino formal não me ofereceu a mínima alfabetização estética. Em contrapartida, por iniciativa familiar, realizei curso técnico de desenho e com isso, na idade adulta, comecei a trabalhar na publicidade, o que me permitiu conviver com artistas renomados como José Zaragoza (1930-2017), Dorinho Bastos, José Luiz Benício da Fonseca, entre outros, e passar a ser muito bem remunerado. Apesar do salário, riqueza de experiências e farto acesso a técnicas e materiais, enfrentava profundo choque ético com os compromissos comerciais daquele setor, de modo que, no nível superior, optei, justamente, pela Educação Artística.

O meu ingresso na vida acadêmica, em 1986, na Universidade São Judas Tadeu, portanto, se deu em meio ao intenso debate questionando o caráter polivalente da formação em educação artística. Alheio à discussão, enfrentava a necessidade de frequentar um curso noturno em instituição privada, na qual, apesar 
de contar com um corpo docente altamente qualificado, não havia nenhum projeto que permitisse que os conteúdos da graduação fossem aprofundados em atividades de pesquisa, como ocorre nas Universidades Públicas.

Além disso, ainda que eu contasse com significativa inserção no mundo das artes plásticas, antes da faculdade havia assistido a poucos espetáculos teatrais e, ao longo do curso, participado de algumas poucas montagens acadêmicas ou amadoras, situação que, numa sociedade orientada pela lógica competitiva, oferecia uma sensação de enorme defasagem.

Agravando a situação, uma vez definido o teatro como área de habilitação, notava a recorrência com que o repertório de formação, constituído esmagadoramente por conteúdos herdados da tradição europeia e destinados à produção de espetáculos, era insuficiente ou inadequado para atender à realidade encontrada no "chão da escola".

Sob outro aspecto, as potencialidades do teatro exerceram influência definitiva sobre a minha identidade estética. Como artista, eu me reconhecia facilmente como pertencente ao campo do Desenho, porém, quanto mais eu me descobria como ator, mais a composição plástica se afirmava, impelindo-me em busca de um ponto de intersecção, nessa geometria artística.

Em meio, e apesar de tais inquietações, compreendi que era necessário investir na formação continuada e, em 1991, ingressei no curso de Especialização em Teatro e Dança oferecido pelo Centro de Artes Cênicas, da Escola de Comunicação e Artes. Contando com um corpo docente formado pelas Professoras Maria Lúcia Pupo, Karen Müller, Cibele Cavalcanti e Ingrid Dormien Koudela, o curso, predominantemente prático, uniu os pontos esparsos, oferecendo sentido à aproximação entre o meu corpo e a visualidade.

Em primeiro plano, faz-se necessário ressaltar, a importância do entendimento da ludicidade no processo de ensino/aprendizagem teatral não constituía novidade para mim, já havia amplamente empregado autores como Peter Slade (1987), Olga Reverbel (1989) e Augusto Boal (1980), mas o sistema organizado por Spolin revelou-se muito mais completo, na medida em que depositava a ênfase sobre o caráter prático e essencial do fazer teatral, 
fundamentado, entre outras coisas, na relação entre atuantes e assistentes. Aplicado com rigor, a experiência com o jogo teatral durante o curso estimulava, alternadamente e em termos físicos, a análise daquele que observava sobre a ação daquele que atuava, em busca da leitura e decodificação dos possíveis significados da ação, independente de padrões estéticos pré-definidos ou fundamentados prioritariamente na oralidade. Livre, portanto, de uma moldura estética específica (FÉRAL, 2015, p. 94), o sistema, não raro, levava às mesmas convenções teatrais, como "deixa", "bastidores", "personagem", "lugar teatral" ou "espaço cênico", "ação". Mas, o segredo se encontra na capacidade de partir do jogo de regras em direção àquilo que se possa se tornar convenção, não o seu contrário. Como o caminho é percorrido movido pela força alcançada devido às exigências da prática, o sistema facilmente proporciona a aprendizagem significativa (AUSUBEL, 1982; FREIRE, 1996) e, como tal, por princípio, deve manter-se aberto à incorporação de recursos de representação adequados à solução dos problemas surgidos no processo.

Nesse sentido, o jogo teatral de Spolin exercia sobre mim papel libertador, pois a fonte da ação, no nível da improvisação, era o meu repertório pessoal e a capacidade de troca em relação às propostas trazidas pelos parceiros de jogo. Para as situações surgidas, e fisicamente manifestadas, não havia certo ou errado em oposição àquilo que parecia a submissão a um acúmulo, por vezes, inócuo, de técnicas reproduzidas, mecanicamente. Não raro, as respostas oferecidas aos problemas de jogo eram trazidas por estudantes que, como eu, tinham menor experiência com as tradições de interpretação teatral, porosos que éramos ao que surgia no "aqui e agora".

O quadro, no entanto, não estaria completo sem que se fizesse referência aos papéis da eutonia (ALEXANDER, 1983) e do método Laban (1978) na formação oferecida pelo curso. Em termos estritamente pessoais, o trabalho de construção da imagem corporal, para alguém que havia experimentado o desenho de anatomia, repercutia como a projeção mental do próprio corpo, reconhecido em suas características particulares e individuais. Nos exercícios de eutonia, independente de virtuosismo, as composições físicas eram exploradas com base 
na economia do movimento ou no tônus adequado, alcançado através da otimização da energia empregada, quando se articulavam, devidamente, as propriedades estruturais da ossatura, os comandos voluntários do sistema nervoso e a suficiente tração muscular. O lugar ocupado pelo método na educação somática guardava absoluta coerência com o caráter inclusivo do jogo teatral, pois foi concebido por Gerda Alexander (1908-1994), em 1957, quando funda a primeira escola de eutonia, na Dinamarca (DASCAL, 2005, p. 27), no contexto de buscas pela expressão individual, em oposição aos modelos padronizados e mecanizados da dança, inclusive em respostas às limitações de sua própria saúde (idem, p. 26).

O mesmo se operava no emprego dos fundamentos do movimento, concebidos no início do século XX, por Rudolf Laban (1879-1958) cuja primeira formação se deu, justamente, no campo da arquitetura. Suas propostas, articulando a relação entre o movimento humano e o espaço circundante, resultaram na "Labanotation" (RENGEL, 2001, p. 92), uma das principais referências para a dança contemporânea. Seus compromissos com a inclusão são identificados na composição da dança coral, onde Laban reunia grande contingente de participantes, unidos na realização de composições acessíveis a qualquer indivíduo, com base nos fatores de movimento, assim como, após a fuga da perseguição nazista, exilado em Londres, redirecionou suas proposições para qualificar o esforço de operários na realização de suas atividades laborais. As notações do movimento, de Laban, são precisamente representadas por desenhos geométricos inscritos no espaço que circunda o corpo do praticante, denominada "cinesfera" (idem, p. 37).

Tais conteúdos de investigação, do ponto de vista do repertório expressivo, desembocaram na ampliação das possibilidades da fisicalização, uma categoria de ação central no sistema de jogos teatrais, com estreitas relações com a proposta de ações físicas trazidas por Stanislavski (1863-1938), mas experienciadas de forma particular, resultaram com muito maior fluência. Além disso, o índice de coerência se operava no sentido ético e social das propostas de Spolin, surgidas da sua atuação na Hull House, de Chicago, a partir de 1924, sob orientação de Neva Leona Boyd (1876-1963). Responsável pela elaboração de atividades teatrais 
nos parques da cidade, Spolin encontrou as conexões entre as atividades grupais e o jogo colaborativo como fundamentos para o desenvolvimento social e a experiência teatral (CAMARGO, 2002, p. 283).

A riqueza e o crescimento artístico, oferecidos pelo curso de especialização, fizeram do jogo teatral a mais relevante ferramenta para o desempenho de meu papel como educador, tanto em instituições regulares de ensino, como em projetos de formação teatral vinculados à Secretaria Estadual de Cultura, em especial na Oficina Cultural "Alfredo Volpi”, em Itaquera, zona Leste de São Paulo, onde se deu origem à montagem de "O nome do negro". Uma experiência vinculada ao compromisso de garantir o pleno exercício da cidadania, onde a Cultura figurava como direito e, frente ao qual, era fundamental que a construção do espetáculo fosse alcançada a partir das potencialidades expressivas de cada membro daquela comunidade.

O período marca, também, o meu ingresso como docente de nível superior, no curso de Educação Artística, da Faculdade Santa Cecília, em Pindamonhangaba, única instituição a oferecer a habilitação em Artes Cênicas, no Vale do Paraíba. Ao lado do Prof. Joaquim Gama e da Prof ${ }^{\underline{a}}$ Elizete Gomes, pude reformular o Projeto Pedagógico do Curso, incorporando o sistema entre os componentes curriculares, contribuindo para a difusão do jogo teatral.

A eficiência na aplicação das propostas de Spolin foi igualmente comprovada na formação de atores, em diversos cursos técnicos de nível médio nos quais atuei, seja no âmbito da interpretação, seja no plano da encenação, onde amadureci a adoção dos princípios da marcação não direcional. Porém, a mais relevante das minhas experiências teatrais foi realizada ao longo de 12 anos, durante os quais fui diretor artístico do Grupo "Atrás do Grito" de Teatro, entre 1993 e 2015.

Em meu primeiro contato com o Instituto de Artes da UNESP, o curso de Educação Artística oferecia habilitações em Artes Plásticas e Música, alegando-se não haver condições para oferecer Artes Cênicas devido à ausência de "instalações adequadas" para a prática teatral. Em oposição, o Diretório Acadêmico "Manuel Bandeira", presidido por Elisabete Geraldini, investiu na criação de um grupo de teatro no I.A. e pediu minha colaboração. Os estudantes traziam uma colagem 
teatral pensada para o palco e estava reunindo um talentoso elenco, sobretudo, em termos musicais. Ao final de 1993, o espetáculo "Rapsódia Radiofônica" foi apresentado no Instituto de Ciências e Tecnologia, em São José dos Campos e, diante da boa recepção do espetáculo, partimos para a definição das linhas de atuação que viabilizassem a institucionalização da proposta.

A proposta, apresentada, por mim e Geraldini, à Pró-reitoria de Extensão e Cultura, foi prontamente acolhida no Programa de Atividades Culturais, sob o título de "Teatro Didático da UNESP", sob responsabilidade do Prof. Reynúncio Napoleão de Lima, então meu orientador no Programa de Mestrado, do Instituto de Artes. O projeto se destinava a estudantes da unidade acadêmica e a membros da comunidade, na constituição de um coletivo teatral.

A partir de 1995, foram concedidas 3 bolsas, diretamente orientadas por mim, com supervisão do Prof. Reynúncio, destinadas à investigação das propriedades sonoras, visuais e cinestésicas da ação cênica, mas regidas pelos fundamentos do jogo teatral. Além da interpenetração das formas expressivas, o trabalho com a comunidade exigia conceber que a gênese da criação cênica estava situada no espaço elementar de habitação do ser: o seu corpo. Nossas diretrizes repousavam em descobrir e ampliar as potencialidades individuais e estabelecer a cumplicidade entre os corpos, através de trocas mútuas e afastadas de um sistema comprometido com padrões pré-determinados, inclusive, do ponto de vista da multiplicidade do espaço cênico (SOUZA, 2003).

O período à frente do "Atrás do Grito" representou um processo de imersão articulando possibilidades do espaço cênico e de jogo teatral, de modo que há inúmeras possibilidades de reflexão sobre a aplicação dos conceitos definidos pelo sistema. Diante das múltiplas escolhas, dentre os componentes que julgo mais relevantes, esse escrito é oportunidade de destacar, justamente, o valor da "cumplicidade".

Quando Spolin afirma que talento ou falta de talento nada mais seriam do que maior ou menor disposição para experienciar, recorda, ainda, que um ambiente estimulante à liberdade de experimentação é fundamental ao desenvolvimento da expressividade em cena (1982, p. 3). O ambiente, logicamente, não poderia ser 
pensado em termos exclusivamente físicos, mas como espaço de liberdade em relação ao outro. O movimento de trocas, entre o jogador e o professor/diretor, dos próprios jogadores entre si, entre palco e plateia, entre jogador e espaço físico, operava transversalmente em todas as sessões de trabalho que foram desenvolvidas no Instituto de Artes. Nesse sentido, para ampliar o entrosamento, em busca de respostas intuitivas, tanto mais ágeis, quanto maior fosse o exercício da improvisação com base no jogo de regras, os elementos de visualidade, por exemplo, eram confeccionados em sistema de mutirão, por todos os membros da equipe, trabalhando em conjunto. Além de desenvolver habilidades específicas, o sentido de pertencimento era obtido em razão do espírito de cooperação. Os 15 anos de longevidade do grupo demonstram como o sistema é eficaz no processo de formação de grupo, algo tão caro ao teatro.

Outro aspecto relevante se refere ao compromisso de compartilhar resultados na forma de apresentações, sempre procurando adequar as exigências do trabalho ao estágio de amadurecimento da equipe, uma diretriz que correspondeu ao emprego do conceito de avaliação, num nível avançado. Assim, seguiram-se uma gama extremamente diversificada de experiências, entre performances, intervenções e espetáculos teatrais, alguns elaborados em processo colaborativo, dada a afinidade do grupo com a improvisação.

O Grupo "Atrás do Grito" de Teatro cumpriu o seu objetivo, provando a viabilidade da criação da habilitação em Artes Cênicas, ofertada pelo Instituto de Artes em 1997 e reconhecida em 1999. O trabalho desenvolvido na UNESP, com o qual estive envolvido até 2005 , foi coroado de êxito, indubitavelmente, por força da adoção do jogo teatral como eixo norteador de todo o processo de formação e criação.

$\mathrm{Na}$ elaboração do desenho mapeando a minha trajetória, para finalizar minha exaltação, ressalto que, se hoje ocupo um cargo docente na Universidade Federal de Goiás, muito devo ao trabalho com o sistema de jogos teatrais de Viola Spolin, o que faz de mim um de seus defensores mais intransigentes.

Às docentes do curso de Especialização em Teatro e Dança, da Universidade de São Paulo, ofereço a minha mais profunda gratidão. 
Recebido em 05/05/2020

Aceito em 08/06/2020

\section{Referências}

ALEXANDER, Gerda. Eutonia - Um caminho para a percepção corporal. São Paulo: Martins Fontes, 1983.

AUSUBEL, D. P. A Aprendizagem Significativa: a teoria de David Ausubel. São Paulo, Moraes, 1982.

BAKHTIN, Mikhail. A cultura popular na Idade Média e no Renascimento: o contexto de François Rabelais. Trad. Vieira, Y. F. São Paulo: Hucitec/ Editora da Universidade de Brasília, 1987.

BOAL, Augusto. 200 Exercícios e jogos para o ator e não ator com vontade de dizer alguma coisa através do teatro. Rio de Janeiro: Civilização Brasileira, 1980. CAMARGO, Robson Corrêa de. "Neva Leona Boyd e Viola Spolin, jogos teatrais e seus paradigmas", Revista Sala Preta, v. 2, 2002, pp. 282-289.

DASCAL, Miriam. Eutonia. "O saber do corpo". Campinas: Instituto de Artes, Universidade Estadual de Campinas, 2005. (Dissertação de Mestrado em Artes).

FÉRAL, Josette. Além dos limites: teoria e prática do teatro. 1 ed. São Paulo: Perspectiva, 2015.

FREIRE, Paulo. Pedagogia da Autonomia: saberes necessários à prática educativa. São Paulo: Paz e terra, 1996.

LABAN, Rudolf. Domínio do movimento. São Paulo: Summus, 1978.

RENGEL, Lenira Peral. Dicionário Laban. Campinas: Instituto de Artes, Universidade Estadual de Campinas, 2001. (Dissertação de Mestrado em Artes).

REVERBEL, Olga. Jogos teatrais na escola. São Paulo: Scipione, 1989.

SLADE, Peter. O Jogo dramático infantil. São Paulo: Summus, 1987.

SOUZA, Newton de. A roda, a engrenagem e a moeda. Espaço cênico e vanguarda no Teatro de Victor Garcia, no Brasil. São Paulo: Editora da UNESP, 2003.

SOUZA, Newton A. de. Teatro de Rua na Cadência do Samba. O processo de montagem do espectáculo "O nome do negro", em São Paulo. Lisboa: Faculdade de Letras da Universidade de Lisboa, 2019. (Tese de Doutorado. Programa de Estudos de Teatro).

SPOLIN, Viola. Improvisação para o teatro. Trad. Ingrid Dormien Koudela e Eduardo Amos. São Paulo: Perspectiva, 1982. 